\title{
Nephrotic syndrome of childhood: malaria therapy reconsidered
}

In 1952 Gairdner $^{1}$ and Byrne ${ }^{2}$ independently reported that acute infection with malaria could induce a remission of what was then known as nephrosis or type-II nephritis of Ellis. ${ }^{3}$ Gairdner was stimulated to investigate this type of treatment by the long-lasting remissions, amounting to cures, that occasionally followed measles in the nephrotic child ${ }^{4}$, and recently he reported 'a notable case of nephrosis' illustrating the duration of this effect. ${ }^{5}$

In his paper in 1952, Gairdner described 4 children with nephrosis infected with Plasmodium vivax. ${ }^{1}$ The case reports are interesting: 'On 12 January 1949, malarial mosquitoes were applied. . . . On 24 January malarial fever began, the temperature rising to $102^{\circ} \mathrm{F}$. Next day diuresis set in and oedema began to subside rapidly, disappearing completely by 2 February'. However, albuminuria persisted, although in another child it cleared completely. The malarial attacks were terminated by mepacrine. One of the 2 children who did not respond developed renal failure and was shown at necropsy to have crescentic nephritis.

Subsequently, Gairdner and Shute collected the clinical details of the 65 children with nephrosis for whom the Malarial Reference Laboratory had supplied infected blood or mosquitoes. ${ }^{6} 51$ of these were considered to be cases of 'pure nephrosis', of * whom 14 had a complete remission, although 4 of them subsequently relapsed and another 4 had proteinuria at follow-up. There was one death associated with malaria treatment, and 6 patients required transfusion.

These trials of malaria therapy were naturally not controlled, but nevertheless the impression is gained that in some cases there was a close temporal relationship between malarial fever and remission of the nephrotic syndrome. However, these were the years of excitement after the introduction of corticosteroid treatment for the nephrotic syndrome, ${ }^{7}$ and even alkylating agents were looming on the horizon $^{8}$ so that a possible therapeutic effect of malaria was not pursued. Malaria therapy is considered in this Annotation in the light of contemporary understanding of the immunopathogenesis of the nephrotic syndrome.

\section{Terminology}

The nephrotic syndrome consists of a disturbance of glomerular permeability resulting in albuminuria, hypoalbuminaemia, and oedema. Most children respond to treatment with corticosteroids and have only slight histological changes in the glomeruli evident on light microscopical examination. The condition was called 'lipoid nephrosis' by Munk, ${ }^{9}$ but the term nephrosis has been attacked by Oliver ${ }^{10}$ as etymologically meaningless, and the adjective lipoid emphasises an aspect of the disease that is of only secondary importance. Some authors refer to the condition as the 'idiopathic nephrotic syndrome', which implies an optimistic assessment of current understanding of the pathogenesis of other forms of the nephrotic syndrome. Recently the term 'minimalchange nephrotic syndrome' has been popular, but there is a certain illogicality, unfortunately common in the nosology of renal disease, in the use of a pathological term to describe a condition essentially recognised by its clinical features; in many cases a renal biopsy will not be undertaken, and the histological appearances will therefore remain a presumption. The expression 'steroid-responsive nephrotic syndrome' (SRNS) at least has the merit of focusing on the most important objective characteristic of the condition, but has the disadvantage of excluding a few otherwise similar cases which do not respond to conventional corticosteroid regimens. ${ }^{11}$

\section{Immunological aspects}

The pathogenesis of SRNS is not known, but it is tempting to speculate that immunological mechanisms are involved. However, critical laboratory evidence of immunopathogenesis has not been forthcoming, and in cases where immunological abnormalities are observed, it is often difficult to decide whether they are a secondary effect of the nephrotic state or an epiphenomenon of the event that precipitated the relapse rather than an integral part of the pathogenetic mechanism.

Clinical observations. A number of clinical observations have suggested an immunopathogenesis of SRNS. In the first place, relapses are often precipitated by upper respiratory infections. There is an increased incidence of atopy, particularly infantile eczema or hay fever, which was reported in $38 \%$ of the nephrotic children compared with $18 \%$ of age-matched controls, ${ }^{12}$ and there are some well- 
documented cases in which relapses of the nephrotic syndrome were associated with atopic features-such as grass pollen hypersensitivity ${ }^{13,14,15}$ and possibly milk allergy. ${ }^{16}$ The condition is more common in children who have the second series tissue antigen HLA-B12. ${ }^{12}$ The association with HLA-B12 however is weak, with a relative risk of $6 \cdot 3$, but has been confirmed by a further study. ${ }^{17}$ There appears to be an increased incidence of minimal-change nephrotic syndrome in patients with Hodgkin's disease, but in only 5 of the 35 reported cases has the condition been demonstrated to respond to corticosteroids alone. ${ }^{18}$

Pathology. About $80 \%$ of nephrotic children referred to specialist centres respond to treatment with corticosteroids ${ }^{19}, 20$; of these $93 \%$ have minimal histological changes of the glomeruli evident on light microscopical examination and the others have mild mesangial proliferative lesions or focal glomerulosclerosis, although the histological frontiers of 'minimal-change' are difficult to define. $5 \%$ of children with minimal-change histology do not respond to treatment with corticosteroids, although in some of these deep focal sclerotic lesions may have been missed in superficial biopsies.

Immunofluorescence studies do not show glomerular deposition of immunoglobulins or complement components. ${ }^{21},{ }^{22}$ However, immunofluorescent methods may not be sufficiently sensitive, and it is possible experimentally to produce fatal immune complex glomerulonephritis without detectable glomerular deposition of immunoglobulin. ${ }^{23}$ An early report that IgE could be detected in the glomeruli of nephrotic patients ${ }^{24}$ has not been confirmed in other studies. ${ }^{25,} 26$

The actual site of the filtration barrier in the glomerulus which excludes proteins of the size of albumin from the glomerular filtrate is probably the split-pore diaphragm between the epithelial foot processes $^{27}$ which has a complex electron microscopical ultrastructure in which glomerular polyanions containing sialic acid residues play an integral role. ${ }^{28}$ Electron microscopical examination generally shows fusion of epithelial foot processes in SRNS, ${ }^{29}$ but as similar lesions can be induced in dogs by plasma infusions sufficient to cause proteinuria, ${ }^{30}$ and as foot-process fusion persists for several weeks after remission of proteinuria, ${ }^{31}$ it is considered that this abnormality is a consequence rather than the cause of proteinuria. Interestingly, both the aminonucleoside puromycin ${ }^{32}$ and polycations ${ }^{33}$ cause foot-process fusion, and Brenner and coworkers have speculated that the primary event in the nephrotic syndrome is a loss of the glomerular polyanion structure resulting in a diminished restriction of filtration of circulating polyanions, and thus albuminuria, as well as a disturbance of the foot-process structure with fusion. ${ }^{34}$ In this context, the report of a 6-fold increase in serum-free polyamines in nephrotic children is of interest. ${ }^{35}$

Immunoglobulins. The plasma concentrations of IgG, $\operatorname{IgA}$, and $\mathrm{IgM}$ are normal in remission, but IgG and $\operatorname{IgA}$ decrease during relapse and IgM rises. ${ }^{36}$ It has been suggested that $\mathrm{IgM}$ levels remain high in remission, ${ }^{37},{ }^{38}$ but these observations probably result from allowing insufficient time for the effects of the previous relapse to wear off. Plasma IgE is raised in one-quarter of nephrotic children, independent of the state of relapse or remission, ${ }^{12}, 39,40$ and there are also raised levels of IgE antibody to Timothy grass pollen and Dermatophagoides pteronyssinus.

Complement. Total haemolytic complement is normal in these patients ${ }^{21,}{ }^{41}$ as is plasma $\mathrm{C} 3,{ }^{42}$ and there is no immunoelectrophoretic evidence of $\mathrm{C} 3$ conversion in vivo. ${ }^{43}$ Plasma $\mathrm{C} 4$ and Clq levels are generally found to be normal, ${ }^{36,}{ }^{38}$ although there was an earlier report of reduced plasma Clq in some patients. ${ }^{44}$ The low plasma factor B concentration is due to urinary loss, ${ }^{36}$ and has been considered responsible for defective opsonisation of Escherichia coli by nephrotic sera ${ }^{45} \mathrm{C} 3 \mathrm{~b}$ inactivator (KAF) levels are reduced as well. ${ }^{46}$ Immunoconglutinin (IK), an autoantibody to hidden antigenic determinants in C3 and C4 is detectable in nephrotic sera during relapse, suggesting complement activation, ${ }^{41}$ but Mallick found a less consistent relationship between IK peaks and relapse in nephrotic patients. ${ }^{38}$ Smith and co-workers reported that sera from SRNS children in relapse inhibited the formation of EACrosettes by normal human tonsillar B-lymphocytes, suggesting the presence of free or complexed $\mathrm{C} 3 \mathrm{~b} .{ }^{47}$ Taken together, the IK and EAC-rosette data suggest low grade activation of the complement system.

Immune complexes. Recently Levinsky and coworkers reported the detection of circulating immune complexes in the sera of nephrotic children in relapse by a technique dependent on the inhibition of agglutination of IgG-coated latex particles by rabbit IgM antibody to human IgG. ${ }^{48}$ Complexes were detected in relapse and persisted for several weeks after remission; they were thought not to be an artefact of nephrotic sera as they were not detectable in congenital nephrotic patients. The complexes were of moderate size (molecular weight $2-2.5 \times 10^{6}$ daltons), and interestingly did not bind Clq, suggesting that if there is complement activation, it involves the alternative pathway. Immune complexes were 
not however detected in the sera of minimal-change nephrotic patients by a Raji cell radioimmunoassay or by a radiolabelled Clq binding assay, ${ }^{49}$ but it is not at all unexpected for the various methods of immune complex testing to give differing results.

Lymphocytes. The absolute number of circulating T-lymphocytes, recognised by sheep erythrocyte rosette formation, is normal in nephrotic patients, as are the numbers of the subpopulations of T-cells which bind IgM or IgG, although IgG-binding cells increase in response to corticosteroids. ${ }^{50}$ The response of SRNS lymphocytes to phytohaemagglutinin (PHA) is poor, ${ }^{51}$ and the response to the T-cell mitogen concanavallin-A is more depressed than the response to PHA (S. N. Chapman and G. Williams, 1979, personal communication). Moorthy and co-workers demonstrated that nephrotic sera inhibited ${ }^{3} \mathrm{H}$-thymidine uptake by normal lymphocytes in response to PHA or allogeneic mitomycintreated lymphocytes. ${ }^{52}$ However these lymphocyte systems are susceptible to nonspecific influences such as anaesthesia..$^{53}$ Ooi and co-workers described lymphocytotoxins in minimal-change nephrotic sera, but in many other diseases as well. ${ }^{54}$ Leucocyte migration inhibition by nephrotic lymphocytes exposed to a crude antigen from neonatal human kidney cortex has been demonstrated, ${ }^{55}$ but sensitisation to glomerular basement membrane antigens is generally not detectable. ${ }^{56}$ Eyres and co-workers have also reported that lymphocytotoxicity for epithelial cells cultured from neonatal human renal cortex is specifically associated with the minimal-change nephrotic syndrome. ${ }^{57}$ However, lymphocytes are not evident histologically in the kidneys of nephrotic patients, and therefore it is difficult to imagine that such observations are relevant to the pathogenesis of the disorder. Lagrue and co-workers described lymphokine activity in the supernatant of nephrotic lymphocyte cultures which increased vascular permeability on intradermal injection in a guinea-pig, and proteinuria on injection into the renal artery of a rat. They presented pharmacological evidence suggesting that the lymphokine stimulated the kinin system, ${ }^{58}, 59,60$ and there is some evidence that the kinin system is indeed activated in nephrotic patients. ${ }^{61}$ However, $\mathrm{we}^{62}$ have not been able to detect the differences in vascular permeability factor between nephrotic patients and controls as reported by Lagrue and coworkers. ${ }^{58,59,60}$ The data so far presented on lymphocyte function in the nephrotic syndrome are intriguing but do not yet present a coherent picture; Shalhoub's suggestion that the syndrome results from a disorder of T-cell function remains speculative. ${ }^{63}$

\section{Treatment}

Corticosteroids. Corticosteroid treatment of childhood nephrotic syndrome was introduced nearly $\mathbf{3 0}$ years ago but has not been established by controlled trial. ${ }^{7}$ The Medical Research Council conducted a trial in adult nephrotic patients, in which it was noted that there was a trend towards a higher mortality in the prednisone-treated group compared with controls; in patients with minimal change histology the disappearance of proteinuria was more rapid on treatment, but among the controls the proteinuria had nevertheless fallen to $<1 \mathrm{~g} / 24 \mathrm{~h}$ in more than half the patients 2 years after entry into the trial. ${ }^{64}$ The same tendency to natural recovery was evident in nephrotic children before the advent of corticosteroids. ${ }^{65}$ However, the risks of the nephrotic state are such that it would not be justified to withhold corticosteroids for any significant length of time from a nephrotic child, and the effect of corticosteroid treatment in inducing remission is obvious enough for a controlled trial not to be now necessary or appropriate. There is, however, an appreciable need for controlled trials to evaluate different methods of administration of corticosteroids, and many of the recommendations are a normal adrenal response in maintaining remislogists differ. ${ }^{66}$

Two-thirds of the responders will relapse. Leisti and co-workers reported an association between early relapse and a poor cortisol response to ACTH after the first course of corticosteroids, and have demonstrated that $7 \cdot 5-15 \mathrm{mg}$ daily of prophylactic cortisol prevents relapse, emphasising the role of a normal adrenal response in maintaining remission. ${ }^{67,68}$

Immunosuppressives. It is paradoxical that the major role of immunosuppressive agents in the treatment of the nephrotic syndrome of childhood is in that group with the least convincing evidence of immunopathogenesis-that is the corticosteroid-responders and the minimal change corticosteroid-resistant patients. Alkylating agents were first used in $1952^{8}$ and the first report of the use of cyclophosphamide appeared 16 years ago. ${ }^{69} \mathrm{It}$ is well established that cyclophosphamide can prevent relapse of the corticosteroid-responsive nephrotic syndrome. ${ }^{70,}{ }^{71}$ An 8week course of cyclophosphamide in a dosage of $3 \mathrm{mg} / \mathrm{kg}$ per 24 hours results in about $75 \%$ of patients remaining in remission for one year and $50 \%$ for 5 years. ${ }^{72}$ Results are better in older children, but children with HLA-B12 do not fare so well.12, 17 There is no benefit to be gained from longer courses or higher doses, but shorter courses are less effective. ${ }^{73},{ }^{74},{ }^{75}$ Cyclophosphamide is an immuno- 
suppressive drug acting principally on B-cells, ${ }^{76}$ but there is no rigorous evidence to support the general assumption that its effect in SRNS is mediated by its immunosuppressive properties. Chlorambucil in a dosage rising to $0.3 \mathrm{mg} / \mathrm{kg}$ per 24 hours is as effective as cyclophosphamide in inducing a sustained remission. ${ }^{77}$ Azathioprine is not effective in preventing relapse. ${ }^{78,} 79$

Malaria. In the light of this rather fragmentary evidence on the pathogenesis of SRNS, how can we view the possible effect of malaria described by Gairdner? The first explanation to be considered is that malarial fever, like measles, stimulates the pituitary-adrenal axis, and that the remissions are a consequence of this. However, this is not a very satisfying explanation: why should some infections induce remission, while others, particularly viral upper respiratory infections, characteristically precipitate a relapse?

The interaction between malaria and the immune system is complex. ${ }^{80}$ There are the immunological consequences or side effects of the acute infection, for example, the immune-complex deposition responsible for the nephrotic syndrome in African children infected with Plasmodium malariae. ${ }^{81}$ However, of greater relevance is the immunosuppressive effect of malaria. Children infected with Plasmodium falciparum have a diminished response to the $\mathrm{O}$ antigen of Salmonella typhi, to tetanus toxoid, and to meningococcal vaccine, but have normal cellular immune responses. ${ }^{82,83}$ The immune response of BALB/c mice to type-III pneumococcal polysaccharide is abolished by infection with the murine Plasmodium yoelii, ${ }^{84}$ and the antibody response to sheep red cells is blunted by Plasmodium bergei infection without detectable effect on cellular immune responses. ${ }^{85}$ The mechanism of this immune paresis is still a matter for discussion and may involve macrophage function, but it seems that malaria, like cyclophosphamide, has a more profound effect on B-cell than on T-cell function. It is of considerable interest that both $P$. berge $i$ infection ${ }^{86}$ and cyclophosphamide ${ }^{87}$ ameliorate the nephritis accompanying the autoimmune disease of New Zealand black/white $F_{1}$ hybrid mice.

The effect of measles on the immune system is however different, and, as with corticosteroids, there is a more profound effect on T-cell function, reflected in the observation of Von Pirquet who first described depression of the tuberculin response during acute measles infection. ${ }^{88}$ Although the theoretical immunologist would have no difficulty in constructing several hypotheses to encompass the described phenomena, we sadly agree, 25 years later, with Gairdner: 'it is tempting to speculate further on the mechanism of malaria-induced remissions; but, in view of our fundamental ignorance of the cause of nephrosis, such speculations would be nugatory'. ${ }^{6}$

\section{References}

${ }^{1}$ Gairdner, D. (1952). Nephrosis treated by malaria. Lancet, 1, 842-844.

${ }^{2}$ Byrne, E. A. J. (1952). Malarial therapy in lipoid nephrosis. Lancet, 1, 844-845.

${ }^{3}$ Ellis, A. (1942). Natural history of Bright's disease. Lancet, 1, 1-7.

${ }^{4}$ Janeway, C. A., Moll, G. H., Armstrong, S. H., Wallace, W. M., Hallman, N., and Barness, L. A. (1948). Diuresis in children with nephrosis. Comparison of response to injection of normal human serum albumin and to infection, particularly measles. Transactions of the Association of American Physicians, 61, 108-111.

${ }^{5}$ Gairdner, D. (1978). A notable case of nephrosis. Archives of Disease in Childhood, 53, 363-365.

${ }^{6}$ Gairdner, D., and Shute, P. G. (1955). Nephrosis treated by malaria. Results in 65 cases. Lancet, 2, 946-950.

${ }^{7}$ Barnett, H. L., McNamara, H., McCrory, W., Forman, C., Rapoport, M., Michie, A., and Barbero, G. (1950). Effect of ACTH and cortisone on the nephrotic syndrome. American Journal of Diseases of Children, 80, 519-520.

${ }^{8}$ Kelley, V. C., and Panos, T. C. (1952). The nephrotic syndrome in children. I. Clinical response to nitrogen mustard therapy. Journal of Pediatrics, 41, 505-517.

${ }^{9}$ Munk, F. (1913). Klinische Diagnostik der degenerativen Nierenerkrankungen. Zeitschrift für klinische Medizin, 78, $1-13$.

${ }^{10}$ Oliver, J. (1950). Essay toward dynamic morphology of the mammalian nephron. American Journal of Medicine, 9, 88-101.

${ }^{11}$ Barratt, T. M. (1979). The steroid-responsive nephrotic syndrome of childhood: pathogenesis and treatment. Australian Paediatric Journal, 15, 17-24.

${ }^{12}$ Thomson, P. D., Barratt, T. M., Stokes, C. R., Turner, M. W., and Soothill, J. F. (1976). HLA antigens and atopic features in steroid-responsive nephrotic syndrome of childhood. Lancet, 2, 765-768.

${ }^{13}$ Hardwicke, J., Soothill, J. F., Squire, J. R., and Holti, G. (1959). Nephrotic syndrome with pollen hypersensitivity. Lancet, 1, 500-502.

${ }^{14}$ Witting, H. J., and Goldman, A. (1970). Nephrotic syndrome associated with inhaled allergens. Lancet, 1, 542-543.

${ }^{15}$ Reeves, W. G., Cameron, J. S., Johansson, S. G. O., Ogg, C. S., Peters, D. K., and Weller, R. O. (1975). Seasonal nephrotic syndrome. Description and immunological findings. Clinical Allergy, 5, 121-137.

${ }^{16}$ Sandberg, D. H., McIntosh, R. M., Bernstein, C. W., Carr, R., and Strauss, J. (1977). Severe steroid-responsive nephrosis associated with hypersensitivity. Lancet, 1, 388-390.

${ }^{17}$ Trompeter, R. S., Turner, M. W., Barratt, T. M., Kay, R., and Soothill, J. F. (1980). HLA atopy and cyclophosphamide in steroid-responsive childhood nephrotic syndrome. Kidney International, in press.

${ }^{18}$ Moorthy, A. V., Zimmerman, S. W., and Burkholder, P. M. (1976). Nephrotic syndrome in Hodgkin's disease; evidence for pathogenesis alternative to immune complex deposition. American Journal of Medicine, 61, 471-477.

${ }^{19}$ Churg, J., Habib, R., and White, R. H. R. (1970). Pathology of the nephrotic syndrome in children: a report for the International Study of Kidney Disease in Children. Lancet 1. 1299-1302. 
${ }^{20}$ Habib, R., and Kleinknecht, C. (1971). The primary nephrotic syndrome of childhood. Pathology Annual, 6, 417-474.

${ }^{21}$ Drummond, K. N., Michael, A. F., Good, R. A., and Vernier, R. L. (1966). The nephrotic syndrome of childhood: immunologic, clinical, and pathologic correlations. Journal of Clinical Investigation, 45, 620-630.

${ }^{22}$ Michael, A. F., McLean, R. H., Roy, L. P., Westberg, N. G., Hoyer, J. R., Fish, A. J., and Vernier, R. L. (1973). Immunological aspects of the nephrotic syndrome. Kidney International, 3, 105-115.

${ }^{23}$ Germuth, F. G., Valdes, A. J., Taylor, J. J., Wise, O., and Rodriguez, E. (1975). Fatal immune complex glomerulonephritis without deposits. Johns Hopkins Medical Journal, 136, 189-192.

${ }^{24}$ Gerber, M. A., and Paronetto, F. (1971). IgE in glomeruli of patients with nephrotic syndrome. Lancet, 1, 1097-1099.

${ }^{25}$ Lewis, E. J., Kallen, R. J., and Rowe, D. S. (1973). Letter: Glomerular localisation of $\mathbf{I g E}$ in lipoid nephrosis. Lancet, 1, 1395.

${ }^{26}$ Roy, L. P., Westberg, N. G., and Michael, A. F. (1973). Nephrotic syndrome - no evidence for role of IgE. Clinical and Experimental Immunology, 13, 553-559.

${ }^{27}$ Brenner, B. M., Bohrer, M. P., Baylis, C., and Deen, W. M. (1977). Determinants of glomerular permselectivity: insights derived from observation in vivo. Kidney International, 12, 229-237.

${ }^{28}$ Rodewald, R., and Karnovsky, M. J. (1974). Porous structure of the glomerular slit diaphragm in the rat and the mouse. Journal of Cell Biology, 60, 423-433.

${ }^{29}$ Farquhar, M. G., Vernier, R. L., and Good, R. A. (1957). An electron microscopic study of the glomerulus in nephrosis, glomerulonephritis, and lupus erythematosus. Journal of Experimental Medicine, 106, 649-660.

${ }^{30}$ Vernier, R. L., Papermaster, B. W., Olness, K., Binet, E., and Good, R. A. (1960). Morphologic studies on the mechanisms of proteinuria. American Journal of Diseases of Children, 100, 476-477.

31Powell, H. R. (1976). Relationship between proteinuria and epithelial cell changes in minimal lesion glomerulopathy. Nephron, 16, 310-317.

${ }^{82}$ Ryan, G. B., and Karnovsky, M. J. (1975). An ultrastructural study of the mechanisms of proteinuria in aminonucleoside nephrosis. Kidney International, 8, 219-232.

${ }^{33}$ Seiler, M. W., Rennke, H. G., Venkatachalam, M. A., and Cotran, R. S. (1977). Pathogenesis of polycation-induced alteration (fusion) of the glomerular epithelium. Laboratory Investigation, 36, 48-61.

${ }^{34}$ Brenner, B. M., Hostetter, T. H., and Humes, H. D. (1978). Molecular basis of proteinuria of glomerular origin. New England Journal of Medicine, 298, 826-833.

${ }^{35}$ Campbell, R. A., Bartos, D., Bartos, F., Grettie, D. P., Talwalkar, Y. B., and Musgrave, J. E. (1976). Serum free polyamines in human disease by radioimmunoassay (abstract). Pediatric Research, 10, 437.

${ }^{36}$ Anttila, R. O., Barratt, T. M., and Soothill, J. F. (1974). The concentrations of immunoglobulins and complement components in the sera of children with glomerular disease (abstract). Pediatric Research, 8, 901.

${ }^{37}$ Giangiacomo, J., Cleary, T. G., Cole, B. R., Holsten, P., and Robson, A. M. (1975). Serum immunoglobulins in the nephrotic syndrome. A possible cause of minimal-change nephrotic syndrome. New England Journal of Medicine, 293, 8-12.

${ }^{38}$ Mallick, N. P. (1977). The pathogenesis of minimalchange nephropathy. Clinical Nephrology, 7, 87-95.

${ }^{39}$ Groshong, T., Mendelson, L., Mendoza, S., Bazaral, M., Humberger, R., and Tune, B. (1973). Serum IgE in patients with minimal-change nephrotic syndrome. Journal of Pediatrics, 83, 767-771.

${ }^{40}$ Lagrue, G., Wirquin, E., Moretti, J. P., Hirbec, G., Lagrue, R., and Galle, P. (1974). Etudes des IgE sérique dans les néphropathies glomérulaires. Journal of Urology and Nephrology, 80, 795-801.

${ }^{41}$ Ngu, J. L., Barratt, T. M., and Soothill, J. F. (1970). Immunoconglutinin and complement changes in steroid sensitive relapsing nephrotic syndrome of children. Clinical and Experimental Immunology, 6, 109-116.

${ }^{42}$ West, C. D., Northway, J. D., and Davis, N. C. (1964). Serum levels of Beta $\mathrm{I}_{\mathrm{IC}}$ globulin, a complement component in the nephritides, lipoid nephrosis, and other conditions. Journal of Clinical Investigation, 43, 1507-1517.

${ }^{43}$ Soothill, J. F. (1967). Altered complement component C3A $(\beta 1 \mathrm{C}-\beta 1 \mathrm{~A})$ in patients with glomerulonephritis. Clinical and Experimental Immunology, 2, 83-92.

${ }^{44}$ Lewis, E. J., Carpenter, C. B., and Schur, P. H. (1971). Serum complement components in human glomerulonephritis. Annals of Internal Medicine, 75, 555-560.

${ }^{45}$ McLean, R. H., Forsgren, A., Bjornsten, B., Kim, Y., Quie, P. G., and Michael, A. F. (1977). Decreased serum factor B associated with decreased opsonisation of Escherichsia coli in the idiopathic nephrotic syndrome. Pediatric Research, 11, 910-916.

${ }^{46}$ Forristal, J., Iitaka, K., Vahota, E. H., and West, C. D. (1977). Correlations between serum factor B and C3b inactivator levels in normal subjects and in patients with infection, nephrosis, and hypocomplementaemic glomerulonephritis. Clinical and Experimental Immunology, 28, 61-71.

${ }^{47}$ Smith, M. D., Barratt, T. M., Hayward, A. R., and Soothill, J. F. (1975). The inhibition of complement-dependent lymphocyte rosette formation by the sera of children with steroid-sensitive nephrotic syndrome and other renal diseases. Clinical and Experimental Immunology, 21, 236-243.

${ }^{48}$ Levinsky, R. J., Malleson, P. N., Barratt, T. M., and Soothill, J. F. (1978). Circulating immune complexes in steroid-responsive nephrotic syndrome. New England Journal of Medicine, 298, 126-129.

${ }^{49}$ Woodroffe, A. J., Broder, W. A., Theofilopoulos, N., Götze, O., Glassock, R. J., Dixon, F. J., and Wilson, C. B. (1977). Detection of circulating immune complexes in patients with glomerulonephritis. Kidney International, 12, 268-278.

${ }^{50}$ Trompeter, R. S., Layward, L., and Hayward, A. R. (1978). Primary and secondary abnormalities of T-cell subpopulations. Clinical and Experimental Immunology, 34, 388-392.

${ }^{51}$ Schulte-Wisserman, H., Lemmel, E. M., Reitz, M., Beck, J., and Straube, E. (1977). Nephrotic syndrome of childhood and disorder of T-cell function. European Journal of Pediatrics, 124, 121-128.

${ }^{52}$ Moorthy, A. V., Zimmerman, S. W., and Burkholder, P. M. (1976). Inhibition of lymphocyte blastogenesis by plasma of patients with minimal change nephrotic syndrome. Lancet, 1, 1160-1162.

${ }^{53}$ Espanol, T., Todd, G. B., and Soothill, J. F. (1974). The effect of anaesthesia on the lymphocyte response to phytothaemagglutinin. Clinical and Experimental Immunology, 18, 73-79.

${ }^{54}$ Ooi, B. S., Orlina, A. P., and Masaitis, L. (1974). Lymphocytotoxins in primary renal disease. Lancet, 2, 1348-1350.

${ }^{55}$ Mallick, N. P., Williams, R. J., MacFarlane, H., Orr, W. M., Taylor, G., and Williams, G. (1972). Cell-mediated immunity in nephrotic syndrome. Lancet, 1, 507-509.

${ }^{56}$ Macanovic, M., Evans, D. J., and Peters, D. K. (1972). 
Allergic response to glomerular basement membrane in patients with glomerulonephritis. Lancet, 2, 207-210.

${ }^{57}$ Eyres, K., Mallick, N. P., and Taylor, G. (1976). Evidence for cell-mediated immunity to renal antigens in minimalchange nephrotic syndrome. Lancet, 1, 1158-1159.

${ }^{58}$ Lagrue, G., Branellec, A., Blanc, C., Xheneumont, S., Beaudoux, C., Sobel, A., and Weil, B. (1975). A vascular permeability factor in lymphocyte culture supernatants from patients with nephrotic syndrome. II. Pharmacological and physicochemical properties. Biomedicine, 23, 73-75.

${ }^{59}$ Lagrue, G., Xheneumont, S., Branellec, A., Hirbec, G., and Weil, B. (1975). A vascular permeability factor elaborated from lymphocytes. I. Demonstration in patients with nephrotic syndrome. Biomedicine, 23, 37-40.

${ }^{60}$ Lagrue, G., Xheneumont, S., Branellec, A., and Weil, B. (1975). Lymphokines and nephrotic syndrome. Lancet, 1, 271-272.

${ }^{61}$ Kallen, R. J., and Lee, S. K. (1975). Study of plasma kinin-generating system in children with minimal lesion, idiopathic nephrotic syndrome. Pediatric Research, 9, 705-709.

${ }^{62}$ Trompeter, R. S., Barratt, T. M., and Layward, L. (1978). Letter: Vascular permeability factor and nephrotic syndrome. Lancet, $2,900$.

${ }^{63}$ Shalhoub, R. J. (1974). Pathogenesis of lipoid nephrosis: a disorder of T-cell function. Lancet, 2, 556-560.

${ }^{64}$ Black, D. A. K., Rose, G., and Brewer, D. B. (1970). Controlled trial of prednisone in adult patients with the nephrotic syndrome. British Medical Journal, 3, 421-426.

${ }^{65}$ Arneil, G. C., and Lam, C. N. (1966). Long-term assessment of steroid therapy in childhood nephrosis. Lancet, 2, 819-821.

${ }^{66}$ Barratt, T. M. (1978). Nephrotic syndrome. In Paediatric Therapeutics, pp. 81-98. Edited by B. Valman. Blackwell: Oxford.

${ }^{67}$ Leisti, S., Hallman, N., Koskimies, O., Perheentupa, J., Rapola, J., and Vilska, J. (1977). Association of postmedication hypocortisolism with early first relapse of idiopathic nephrotic syndrome. Lancet, 2, 795-796.

${ }^{68}$ Leisti, S., Koskimies, O., Perheentupa, J., Vilska, J., and Hallman, N. (1978). Idiopathic nephrotic syndrome: prevention of early relapse. British Medical Journal, 1, 892.

${ }^{69}$ Coldbeck, J. H. (1963). Experience with alkylating agents in the treatment of children with nephrotic syndrome. Medical Journal of Australia, 2, 987-989.

${ }^{70}$ Barratt, T. M., and Soothill, J. F. (1970). Controlled trial of cyclophosphamide in steroid-sensitive relapsing nephrotic syndrome of childhood. Lancet, 2, 479-482.

${ }^{71}$ Spitzer, A., Gordillo-P, G., Houston, I. B., and Travis, L. B. (1974). Prospective, controlled trial of cyclophosphamide therapy in children with the nephrotic syndrome. Report of the International Study of Kidney Disease in Children. Lancet, 2, 423-427.

${ }^{72}$ Barratt, T. M., Bercowsky, A., Osofsky, S. G., Soothill, J. F., and Kay, R. (1975). Cyclophosphamide treatment in steroid-sensitive nephrotic syndrome. Lancet, 1, 55-58.

${ }^{73}$ Barratt, T. M., Cameron, J. S., Chantler, C., Ogg, C. S., and Soothill, J. F. (1973). A comparative trial of 2 weeks and 8 weeks cyclophosphamide in steroid-sensitive relapsing nephrotic syndrome of childhood. Archives of Disease in Childhood, 48, 286-290.

${ }^{74}$ Cameron, J. S., Chantler, C., Ogg, C. S., and White, R. H. R. (1974). Long term stability of remission in nephrotic syndrome after treatment with cyclophosphamide. British Medical Journal, 4, 7-11.

${ }^{75}$ Cameron, J. S. (1978). Immunosuppressive agents in the treatment of the nephrotic syndrome. In Pediatric Nephrology, volume 5, pp. 231-246. Edited by J. Strauss. Stratton Intercontinental Medical Book Corporation: New York.

${ }^{76}$ Berenbaum, M. C. (1975). The clinical pharmacology of immunosuppressive agents. In Clinical Aspects of Immuno$\log y$, third edition, pp. 689-760. Edited by P. G. H. Gell, R. R. A. Coombs, and P. J. Lachmann. Blackwell: Oxford. ${ }^{77}$ Grupe, W. E., Makker, S. P., and Inglefinger, J. R. (1976). Chlorambucil treatment of frequently relapsing nephrotic syndrome. New England Journal of Medicine, 295, 746-749.

${ }^{78}$ Abramowicz, M., Arneil, G. C., Barnett, H. L., Barron, B. A., Edelmann, C. M., Jr, Gordillo-P, G., Greifer, I., Hallman, N., Kobayashi, O., and Tiddens, H. A. (1970). Controlled trial of azathioprine in children with nephrotic syndrome. A report for the International Study of Kidney Disease in Children. Lancet, 1, 959-961.

${ }^{79}$ Barratt, T. M., Cameron, J. S., Chantler, C., Counahan, R., Ogg, C. S., and Soothill, J. F. (1977). Controlled trial of azathioprine in treatment of steroid-responsive nephrotic syndrome of childhood. Archives of Disease in Childhood, 52, 462-463.

${ }^{80}$ Lancet (1978). Editorial: Malaria and immunology. Lancet, 2, 974-975.

${ }^{81}$ Houba, V., Allison, A. C., Hendrickse, R. G., de Petris, S., Edington, G. M., and Adeniyi, A. (1970). Immune complexes in the nephrotic syndrome of Nigerian children. In Proceedings of the International Symposium on Immune Complex Diseases, Spoleto, 1969, pp. 23-35. Edited by L. Bonomo and J. L. Turk. Carlo Erba Foundation: Milan.

${ }^{82}$ Greenwood, B. M., Bradley-Moore, A. M., Palit, A., and Bryceson, A. D. M. (1972). Immunosuppression in children with malaria. Lancet, 1, 169-172.

${ }^{83}$ Williamson, W. A., and Greenwood, B. M. (1978). Impairment of the immune response to vaccination after acute malaria. Lancet, 1, 1328-1329.

${ }^{84}$ Wedderburn, N., and Dracott, B. N. (1977). The immune response to type-III pneumococcal polysaccharide in mice with malaria. Clinical and Experimental Immunology, 28, 130-137.

${ }^{85}$ Greenwood, B. M., Playfair, J. H. L., and Torrigiani, G. (1971). Immunosuppression in murine malaria. I. General characteristics. Clinical and Experimental Immunology, 8, 467-478.

${ }^{86}$ Greenwood, B. M., and Voller, A. (1970). Suppression of autoimmune disease in New Zealand mice associated with infection with malaria. I. (NZB x NZW) F1 hybrid mice. Clinical and Experimental Immunology, 7, 793-803.

${ }^{87}$ Russell, P. J., Hicks, J. D., and Burnet, F. M. (1966) Cyclophosphamide treatment of kidney disease in (NZB $x$ NZW) F1 mice. Lancet, 1, 1279-1284.

${ }^{88}$ von Pirquet, C. (1908). Das Verhalten der kutanen Tuberculin-reacktion während Masern. Deutsche medizinische Wochenschrift, 34, 1297-1300.

T. MARTIN BarratT

Department of Immunology, Institute of Child Health, 30 Guilford Street, London WC1N 1EH 